\title{
OPEN
}

\section{7 \\ The Financial Model of the Audiovisual Industry}

\begin{abstract}
All audiovisual sectors are characterized by financial models which only in rare circumstances refer to intermediaries and to financial markets. Financial sources come from, primarily, public funds and from the pre-sales of copyrights to other businesses of the industry.

This chapter describes the most adopted models of negotiation of copyrights exploitation in the audiovisual industry, differentiating the television, film and web sectors. Being the financial sources correlated to pre-sales of future profits, the chapter analyses the different sales agreements between majors and broadcasters, and the distribution deals between distributors and independent producers.
\end{abstract}

La Torre, Mario. The Economics of the Audiovisual Industry: Financing TV, Film and Web. Basingstoke: Palgrave Macmillan, 2014. DOI: 10.1057/9781137378477.0012. 


\subsection{Introduction}

The financial model of the audiovisual industry changes in relation to the sector and to the type of product. Financial sources come from, primarily, other businesses of the sector or from public funds. And only in rare circumstances does the term refer to intermediaries and to financial markets. Nevertheless, television, cinema and web sectors have developed financial models which mark themselves in relation to the nature of the market players and to the features of the products. Broadcasters find their primary source of financing in selling advertising time, even if public broadcasters can also count on state financing and, with pay TV, on subscription fees. Movie producers avail themselves of public funds and pre-sales of copyrights exploitation managed by distribution companies that, often, anticipate a quota of the sales to the producers. Filmmakers active on the web do not adopt a structured financing model; considering that the greatest section of the native web audiovisual products are self-financed, financial dynamics related to the web are conditioned by the nature of the product. OTT services active in the web market are adopting the same dynamic of broadcasters, catalysing resources through advertising and subscription fees.

The assumption behind the different financial models is that audiovisual products can generate revenues in relation to copyright exploitation. In the light of the above, this chapter focusses on the most adopted models of negotiation of copyrights in the audiovisual industry, differentiating the television, movie and web sectors. Due to the great commercial potential connected to television rights, we have experienced a market in which the role of television broadcaster has become relevant also for other sectors. The entry of other players, active on the web through the offer of non-linear audiovisual service, is determining a new scenario where financial resources coming from advertising and subscriptions are shifting from traditional broadcasters towards the new media, mainly the OTT services. Moreover, OTT players are also beginning to produce their own programmes, and it is plausible that, in the next future, they will partially adopt a broadcaster business model integrated with the SVoD business model. The analysis developed in the chapter, with reference to traditional broadcasters, could fit partly to the emerging business model of OTT players. 


\subsection{Broadcasters negotiating TV copyrights in the domestic market}

Television broadcasters attain the availability of the products, which they insert in their programming, producing or buying them. Production and purchase are, generally, financed by personal resources coming, primarily, from advertising proceeds; from subscription taxes, in the case of public television or pay television; and from government transfers for public broadcasters.

The primary role taken on by television broadcasters in the audiovisual industry is born, above all, from the economic availability recorded in the phases of economic growth. The mechanism is easy to understand. The television channel broadcasts the programmes, the public follows them and the audience is the "merchandise" which advertising agencies negotiate. A programme which can gather a greater audience picks up more advertising and, consequently, being more attractive to advertising agents, has at its disposal a higher budget to be produced or purchased. Lastly, is the company that buys the advertising which finances the television product. The final consumer of the television product is represented by the advertising agent who in time has taken on the role of main funder. Such financial dynamics, typical of commercial television, are valid also for public broadcaster, which today can count on government funds less and less.

Since the gathering of television advertising depends on the ability of other businesses to invest in advertising, and this, in turn, depends on the macroeconomic cycle, generally, the financial availability of the broadcaster is greater in the phases of economic expansion, while it registers a reduction in the contraction phases of the economic cycle. The extensive economic cycles recorded in the 8os in developed countries, and lasting almost 30 years, have handed to television important financial resources from advertising. The other types of audiovisual firms have not been able to count on such significant financial resources, and this circumstance has made television broadcasters the strongest financial players on the market, and those apt to condition the production and the price of a great range of audiovisual products, even if not primarily related to television exploitation.

The main financier of the television product is the firm which buys advertising; it represents the true price-maker of the market of television copyrights; 
production budgets and purchase prices of television products are, this way, strongly correlated to the macroeconomic cycle and to the financial availability of advertisers. This also affects production budget and price of cinema products.

To understand the financial dynamics of a television product - and somehow of cinema ones - we need, therefore, to understand the mechanism of emphasizing the value of the product in the eyes of firms which buy advertising time and understand how this mechanism could be coherent with editorial policies of broadcaster. To this objective, it is necessary to introduce the concept of television programme schedule. The understanding of such mechanism will be functional also in valuing products apt for other markets, like those in the cinema field, but we find in television copyrights the most important exploitation market.

\section{Television product: value and programme schedule}

The commercial potentialities of the television product contribute strongly to condition its value, may it be expressed in production costs or purchase price. Other than the artistic aspects of the product, the commercial potentialities depend also on the broadcaster's negotiation ability and, above all, on its editorial policies. The tool which translates in concrete terms the editorial policies of a television firm is the television programme schedule. The TV schedule is the tool through which television programming is accomplished, which has the aim to place the programmes in a specific temporal space for broadcasting. This fact is of fundamental importance in the value of a programme. The day and the viewing time during which the programme is broadcasted conditions the number of potential viewers and, therefore, it could make the product more or less attractive in the eyes of advertising agents.

The use of television by viewers is seasonally characterized, which determines audience figures at different times of the year, of the week, of the day. Since television consumption varies in time, and the different viewing times address a diverse number of viewers, and a different make up of it, the television firm has the objective of placing the programmes in more adequate time-bands according to programming policies. Considering programming, the year is divided in seasons (Fall-Winter, Spring and Summer), the week is divided among working days and holidays, the day in time-bands. In particular, a programming day is divided in three main time-bands: day-time, prime-time and night-time. Day-time 
corresponds to a time-band which goes from morning until night and, generally, it has an average audience level; prime-time is that of dinner time and is identified as the highest audience time-band, night-time is the night-band, which corresponds to reduced viewing figures.

The main aim of the television firm is to maximize the viewing figures on all time-bands, and in particular on prime-time. Public television and commercial television try to reach the aim of the viewing data having to associate it to different missions of the firm. Public television, for example, has to conciliate the aim of the audience figure with that of access, that is, the greatest use of television by all target viewers; commercial television, on the contrary, can reach the audience target concentrating only on specific segments of viewers. The more the broadcaster finances itself with advertising, the more it has the necessity to reassure to advertisers the level of audience guaranteed, and for which they have paid. Essentially, advertisers pay for advertising space in relation to the type of programme and the time-band of the programme itself; the price paid by the advertisers is valued according to the viewing figures foreseen. The television firm has to, therefore, try to reach the level of guaranteed audience, without falling too much below, but without going overboard to avoid free public contact. The number of viewers can be measured thanks to various variables:

a) average viewing, that is the average number of spectators present in a determined time interval;

b) contact, that is the number of times that the spectators have tuned in on a channel in a determined time space;

c) share, that is the percentage of spectators who are tuned on a single broadcasting in a determined time interval in relation to all the spectators who, at the same interval, are watching television.

Independently from the used calculation variable, it is always true that the advertising agent is willing to pay more for programmes which bring home the greatest audience. Therefore, the general rule at the base of TV programme schedule policies is that the cost of a programme should be adequate to the hosting time-band, and therefore, lastly, to the profits obtained from the selling of advertisement.

Theoretically, for commercial television, and in part also for public ones, since the programmes are financed by advertising, and advertisers pay according to viewing data, the programmes must cost considering the audience figures which presumably they can obtain. 
The cost of a television programme - whether it is a production cost or a purchase cost - has to consider the programming logic. Each segment of time has a different commercial value, and the profits are functions of the segment of time: it goes without saying that programming has to be based on a reliable estimation of foreseen audience figures and the cost of a programme has to be coherent with the time-band in which it will be placed.

The cost of a television product, expressed in terms of production costs or the purchase price, is correlated to its position in the programming. A different placing can bring about, for the same product, a different value.

There is not a cost and a sole price of a television product, but a different cost and a different price considering the placing of the product within the schedule programmed by the television firm. The same product can be valued differently, either by the same firm or by different broadcaster, depending on the programming time-bands in which it is inserted.

This general rule is not, likewise, always pursuable; different variables exist which can determine variations of cost and of price from the average one of the programming time-band originally individualized.

First of all, we consider the efficiency in the make-up of the TV schedule. The broadcaster, indeed, tends to satisfy the advertising agent, counting, alternatively, to maximize the difference among revenues and costs, or to minimize the audience costs. The more the television firm is able to place a product in the viewing time-band which maximizes the difference between revenue and costs, or minimizes the audience cost, the more it will be able to profit on the product; alternatively, it could, using that profit, produce more expensive products, or acquire products at more expensive prices.

The efficiency in the build-up of the programme schedule allows, at even advertising revenues, to maximize margins or, alternatively, to have higher budgets for producing and purchasing the products.

The build-up of the TV programme schedule is, also, conditioned by the firm's internal and external variables; among the internal ones the image of the channel stands out (that is its stable style in time), the identity of the channel (represented by the type of audience it refers to) and the logical sequence of the schedule, according to which a programme cannot be placed in whatever time segment. Among the external ones, the demand of advertising spaces coming from advertisers becomes 
significant, the availability of the adequate product, the programming of competitors, the audience humour.

The result is that, taking into account the TV schedule, the value of a television product, in terms of production costs or of price, is influenced from (Figure 7.1):

a) the availability of financial resources coming from advertising: in times characterized by positive economic trends, the advertising gathering assures greater resources and television firms can opt for more expensive programmes; for this reason, it is easy to find higher production budgets and average purchase prices in expansive economic phases and lower budgets and average prices decreasing in receding economic phases;

b) the necessity to satisfy the needs of advertising agents: the restriction of having to assure to the advertiser the viewing result promised can lead to the need of having to produce or purchase, however, a specific product with the risk of having to provide high production

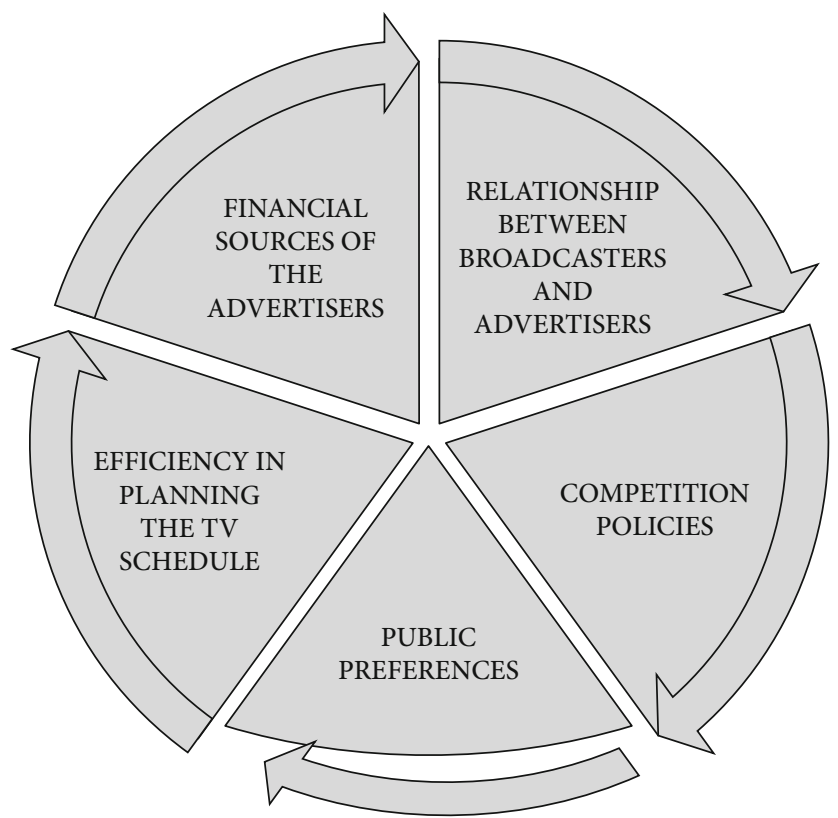

FIGURE 7.1 TV schedule and determinants of value of $T V$ products 
budgets or high purchase prices, and of having to accept packaged purchases, which include other than sought-after products and also less attractive products;

c) the necessity to answer to the programming of competitors: having to face the editorial choices of competitors can create the need to carry out an aggressive programming - or an anti-programming which can result in an increase of costs related to producing or buying well known products, able to contrast those shown by competitors, or to deprive competitors of the availability of certain programmes;

d) the uncertainty related to the mood of the audience: the necessity to obtain a positive audience answer can lead the television firm to allocate in different programming time-bands products of higher quality to that of the average of the group; it comes down to, that in some circumstances, the production and the purchase cost of the products is not proportioned in relation to the programming time-band in which it is inserted.

The value of a television product is inspired to editorial programming, but it is conditioned by the efficiency in the build-up of the TV programme schedule, by the financial availability of advertisers, from the relationship of the broadcaster with the suppliers and from competitors' policies. The combined result of such variables do not allow the identification of a value, and so of a cost and of a price, for any single product, nor for the build-up of benchmark values of reference.

The logic of the build-up of the programme schedule, nevertheless, impugns the value for singular titles and moves the plan of valuing of the television product on a portfolio approach: or more than on the evaluation of the single product, the television firm operates a value of product pockets by audience time-grids, following a logic of crosscollateralization of revenues, according to which the lower revenues recorded on certain products and on specific audience time-bands are subsidized by the greater revenues obtained by other products on other programming bands.

The modern logic of TV programme schedule moves towards the crosscollateralization of revenues and makes the identification of a value of a single title less significant; it becomes meaningless, however, also the definition of a benchmark value for homogeneous products, even when placed within the single programming bands. 


\section{Business models and negotiation of TV rights}

The negotiation of television copyrights within the domestic market takes on different characteristics and different signs in relation to the business model. When the television firm is also producer, the right of exploitation is already in its title. In this case, the negotiation happens between the broadcaster and advertising concessionaires and the broadcaster becomes the seller. This is so, naturally, even in the case of productions given under contract to small companies, because the broadcaster keeps the title of the copyright. In rare cases, some independent producers can find themselves in the position of producing autonomously fortunate TV series, or movies, which are the object of negotiation with national TV broadcasters. Only in this case, the right of exploitation is object of negotiation between the producer and the broadcaster, and it becomes the buyer. In this case, the value of such right is directly connected to programme schedule policies of the broadcaster, and to the product's success with its audience, but it is also strongly conditioned by the negotiating strength of the parts.

\subsection{Broadcasters negotiating TV rights in the international market}

\section{The structure of the market for international sales: United States vs. Europe}

On the foreign market, the negotiation of television copyrights exploitation becomes peculiar. To understand better the negotiation of television copyrights on international markets, it is necessary to start from the structure of the demand and of the supply in such markets. These can be classified in demand-driven and supply-driven markets.

For European producers, for example, the access of their product on the international market is a complex question. European products, generally, have a strong local artistic matrix and, often, are conditioned by the native language; they present, however, a reduced level of universality and a low potential of exportation. For this reason, with the due exceptions, the foreign market represents a minimum quota of proceeds of a European audiovisual product.

The European market of television copyrights is substantially demand-driven; for European broadcasters, negotiations are mainly finalized to buying a foreign product, rather than selling a domestic product. 
On the contrary, the American audiovisual industry is among the few which registers high levels of exports of its own product. Even if, in time, the trend of foreign sales of American products has undergone diverse variations, it is possible to say that the American market is supply-driven.

The American market of television copyrights is substantially supply-driven; for American broadcasters the negotiations are oriented primarily to the sales of national products.

The structure of the market allows identification of some characterizing elements of the international market of television copyrights. Traded products are primarily those of the fiction type, more apt to be exported and ready to meet the interest of viewers in diverse geographic areas. Since the market of copyrights referred to foreign products needs a specific knowledge of the foreign market, the commercial chain foresees, generally, the presence of third parties who mediate among producers and buyers.

Considering such scenery, the value of the product is essentially a value referred to the price of purchase; only in the case of international participation and co-productions, for the broadcaster the value of the product has also a dimension connected to the cost of production and to the sale price of the copyrights.

The price of the copyright, other than being affected by the contractual strength of the parts, and of the programming policy of the broadcaster, is strongly conditioned by the complex commercial chain and from a relevant degree of informative asymmetry among buyers and sellers.

The different nature of European and American markets has led to a different distributive structure of the same: the first integrated by television firms, the second by distribution firms.

Substantially, since American television firms do not buy in a significant way foreign products, in the United States the international television market is sales-oriented, so supported by the interest of producers to sell: are, than, the majors that, through their subsidiaries or through third-parties operators, try to place their products abroad.

In Europe, the international television market is purchase-oriented (buy-oriented), since television firms tend to get abundant foreign product to insert within their own channels.

The union of two markets with opposing needs (of sales the American one, of purchase the European one) and with differently integrated distributive structures (of production the American one, of distribution 
the European one) has determined a lengthy commercial chain which unwinds through more intermediaries and produces numerous negotiating steps.

\section{Actors active in the market of international sales}

The international market of television copyrights today is characterized by the existence of a compound commercial chain in which three categories of subjects operate: the production firms, the third-party operators that become intermediaries among producers and buyers and that can assume different roles and functions, and the television firms.

Producers are essentially represented by the so called "international majors", in particular the American ones, able to furnish continuously universal and spectacular product and content, so to have success at the international level, not only domestic. The role of independent producers is, on the contrary, classified as marginal and characterized by a sporadic presence attached to single products.

Among third-party subjects, it is possible to classify three categories of operators: the agents, the distributors and the intermediaries.

The agent represents the less structured figure; it identifies itself with a person, or a firm, that, stemming from a formal mandate of representation - or informally - functions as an intermediary between the production of which it takes care of the interests and a local broadcaster, probing and verifying the interest of the broadcaster to purchase specific products. The agent does not get involved in a sale contract, which is signed directly by the parties, and does not take on any risks or obligations. At the base of its mediation, the agent asks for a fee calculated as a percentage of the sale price. The business between the agent and the producer ends with the conclusion of the contract and the settlement of the agreed compensation.

The distributor is a specialized firm in the acquisition from the producer of the licencing copyrights of the work, for specific areas and for defined periods and in the exploitation of such copyrights. In the distribution deal the producer and the distributor define the characteristics of the deal and the role of distribution; the sales agreement establishes the terms of the deal between the distributor and the purchasing television broadcaster.

Generally, the financial role of the distributor is to cover the distribution expenses; sometimes, the distributor anticipates to the producer part of the future revenues assuring him a minimum guarantee. 
The possibility of a missed sale, or of a sale at a lower price from what expected, exposes the distributor to the risk of losing the expenses incurred, and of the minimum guarantee. Even the producer is exposed to the risk of not having any revenues from the sale, if the amount of the sale is not enough to cover what is due to the distributor to cover the expenses and as a distribution fee.

Summarizing, the distributor takes risks, but has a limited risk exposure; there is an economic and calculated connection which connects the producer and the distributor during the sale period; the distributor has to report to the producer a detailed account of revenues and their sharing.

The intermediary is represented by a firm, or more rarely by a person, who buys from the producer the copyrights of one or more products, for a specific time period and for specific areas. Substantially, we are facing a subject who assumes the property of the copyrights, making a purchase preceding a future sale (so it does not buy on commission), and takes on the risk of no sales, or the risk that what has been bought will not be "placed on the market"; the risk is that the purchased merchandise would remain "in stock". This role coincides with a pure intermediary figure defined "dealer", which in the audiovisual industry is known as "entrepreneur", to distinguish it from simple agents and from distributors. For the entrepreneur, however, the initial financial pledge coincides with the full price of transfer of the copyrights of exploitation and with the necessary expenses to sell the copyrights on foreign markets.

Generally, resorting to an intermediary is extremely useful because the intermediary who operates as entrepreneur, contrary to the agent and to the distributor, frees the majors of numerous operational, economic, financial and legal risks, by accepting them. In particular:

a) the operational risk, referring mainly to the predisposition and to the handing over of materials of the product sold apt to the needs of the buyer for the specific area, is transferred to the intermediary;

b) the financial risk is reduced because the sale to the intermediary happens in advance - often even before finding the effective final buyer, and often even before the product is made; the financial dynamics of payments of the majors are, so, attached to the relationship between major and intermediary, and only indirectly to those between intermediary and buyer; 
c) the economic risk of the sale, is cancelled because it is transferred to the intermediary;

d) the currency risk is void because transferred to the intermediary: between major and intermediary the contract is, however, always regulated in money of the major;

e) the legal risk is void because transferred to the intermediary who stipulates the contract with the buyer;

f) the fiscal risk - understood as possible application of taxes on revenues coming from the exploitation abroad of the copyrights is void because transferred to the intermediary;

g) the monitoring of proceeds flow (monetary risk) is taken care of at a domestic level because it is referred only to dealing between major and the intermediary;

h) the book-keeping for a single title is negotiated with the intermediary (allocation risk).

Considering the risks, the intermediary is invested of a significant bargaining power in the negotiation with the broadcaster - resulting conditioned only for the duration of the availability of the right and the geographical areas where he can act - and he is independent from the major in defining the sale conditions to apply. The sale contract which the intermediary stipulates with the buying broadcaster is not governed by the producing major that supplies the product even if, unavoidably, it is affected by the financial-economic and contractual conditions existing between major and intermediary. Considering so, the potential profit of the intermediary does not foresee a "cap" from the original contract of purchase of the product and, theoretically, there are no limits, other than what can derive from the dynamics of the market. Therefore, in the market of television copyrights a final price imposed or suggested by the producer and the distributor is not recognized, as it is for some industrial products. The intermediary can act at his own discretion to set up the mark-up and the final price of a certain product and can at his own discretion differentiate it by areas. So it happens, then, that the same product could register different sale prices within different areas, either if such areas have as reference the same intermediary, or in the case - more obvious - in which different intermediaries take care of different areas.

The intermediary who operates as entrepreneur takes care personally of the contract with the broadcaster and is not subject to any cap from the major on 
the final price that he could ask to the purchasing television broadcaster. The same intermediary is free to apply, for the same product, different prices to broadcasters operating in different countries.

What was said is true, specifically, for the intermediary entrepreneur, for the figure which corresponds to the dealer and that, not inverting the business cycle, takes on the financial and unsold warehouse risk. It can also happen that on the market are found intermediaries operating using an inversion of the business cycle that from "production-sale" transforms to "sale-production". It is always an entrepreneur who, but, in this case, buys from the major or from independent producers the rights of exploitation only when he has a specific request from a foreign broadcaster. This happens, in particular, when a request of specific products is put forward directly by the broadcaster, already a client of the intermediary. In such circumstances, the intermediary carries out a "short selling", that is the sale of a product not yet in stock. Normally, to manage the risk of a "short selling", the intermediary tends to combine as much as possible the timing of the sale contract with the purchase contract; it can happen, in such a scenario, that the two prices - of sale from the major to the intermediary and of purchase of the broadcaster from the intermediary are contextually negotiated. Such circumstance can be found, above all, in contexts in which the relationship among intermediaries and clients has become solid in time, and in which the intermediary is not alone in proposing its own products in portfolio, but the client itself commissions some specific titles according to the needs matured within the firm. In such cases, either to safeguard the relationship with the intermediary, to avoid the dispersion of shopping around, or because, more often, it is a restricted number of titles, the broadcaster prefers however to resort to the intermediary, preferring him to the direct purchase from the major. It results in a dynamic of the make-up of the price more similar to the typical one of the agent.

Television firms active in different areas distinguish themselves for two essential variables: the technological paradigm, which determines the modality of broadcasting the programme, and the structure of the financing. In relation to the first aspect, it is possible to distinguish among cable, terrestrial, satellite and digital television; in relation to the economic criterion, we need to distinguish public firms and commercial television.

Each television firm, independently from its own nature and from broadcasting technologies, has the need to supply itself with products to 
place in its programming. However, the combination between economic and technological variables which characterize it conditions strongly the policies of pricing. There are three variables to point out:

a) the degree of vertical integration of the firm: this can cover all or part of the value chain of the sector, from the creation of content to production, from the multimedia packaging to the offer of extra services, until the distribution and the furnishing of the infrastructure for transmitting the signal;

b) the level of multi-channels and the number of programmes: television firms are different due to the number of channels and the number of programmes; the different modalities of broadcasting bring about various costs and allow different availability of channels;

c) sources of funding: public television finds its financing primarily in public funds and in subscription fees and, secondly, in commercials coming from private firms; commercial television has as its exclusive resource advertising; pay television is financed either by advertising or thanks to subscriptions.

It is understandable how the three variables strongly affect the pricing adopted by the firm. A greater degree of vertical integration makes the firm more autonomous from the purchase function and gives it a strong negotiating stance; a greater level of multi-channels and of programmes increases the need of the product and puts the firm in a weak condition in relation to the seller; the great or minor dependence from advertising resources connects the ability of purchase to the variance of the economic cycle: positive economic trends translate in a greater advertising gathering and increase the potentiality of expenditure, negative trends lessen the budget available for purchases.

Substantially, the characteristics of the television firm determine different needs of product, different bargaining strengths and different volumes of expenditure. The result is that, on the international television market, and within single countries, various firms can endure, for the same product, purchasing prices strongly differentiated, of which each one can be coherent with the organizational and economic structure of the firm itself.

The structure of the television firm conditions the pricing of the product to be bought. When on the market there are firms with a different structure and a different volume of expenditure, there is neither a sole price for the same product, nor for homogeneous products, but each price has its own economic rationality. 


\section{Typologies of deals and agreements for international sales}

The negotiating mechanisms of television copyrights on international markets follow procedures which have consolidated themselves in time and have been dictated, mainly, by the distributive structure of markets oriented to sales and by markets oriented to purchasing, as to also by the specific needs of counter-parties.

It is clear how the different distributive structures generated by American producers, oriented to sales, have met up with those of European television, oriented to purchasing, and as to how such meeting has determined the consolidation of progressive negotiating steps, mediated by third-party intermediaries in relation to producers and buyers, with a consequent increase of the number of commercial steps.

In such a scenario, the true market presents a multitude of negotiating schemes which meet the different needs of sellers and buyers.

The objectives of seller and buyer are different in relation to three elements:

a) the type of product;

b) the amount of product;

c) the conditions of exploitation of the product: geographical area, period of exploitation, number of runs.

The producer wants to sell, together with a quality product, also the less successful product, to sell all the available product and to offer the least possible number of licenses and reruns. The buyer is interested in purchasing the best product, to get only the product which appeals to him and to obtain the greater number of licenses and reruns.

The necessity to conciliate the opposing needs of sellers and buyers makes it necessary to resort to different negotiating schemes in view of the alternative which best combines the needs of counter-parties. The presence of agents, distributors and intermediaries on the international sales market is principally justified by such necessity because in different hypotheses it corresponds to the best solution of negotiation.

Among the many alternatives, the most significant ones, and which are greatly relevant in this case, are connected to two specific negotiating options:

a) the output deal and the volume deal stipulated directly among majors and television broadcasters;

b) the package deal stipulated among intermediaries and broadcasters. 


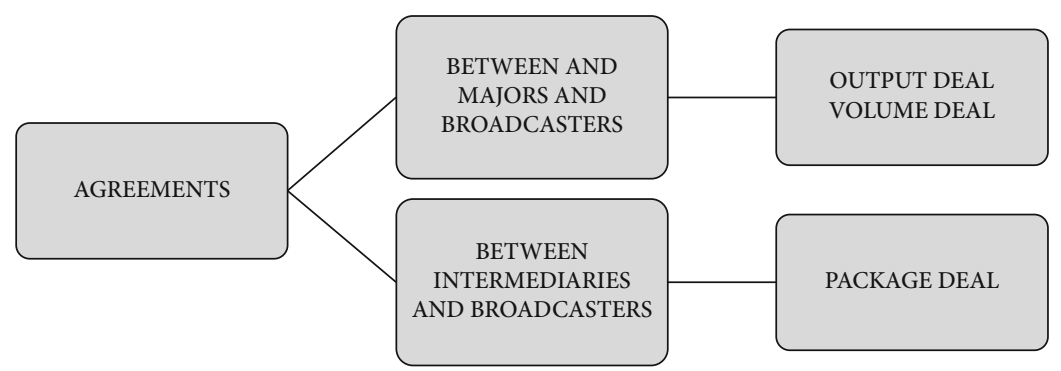

FIGURE 7.2 Types of agreements for the sale of TV copyrights

Generally television firms use both options, which can take on different meaning, due to the conditions of the market and the strategies adopted by the television firm (Figure 7.2).

\section{Sales between majors and broadcasters: output deal and volume deal}

The contracts stipulated by television firms directly with the majors have, generally, the objective of covering the structural needs of product of the firm. Substantially, the broadcaster looks, through a direct deal with the major, to assure itself a supply at the source. The output deal, in fact, establishes a pledge by the firm to buy, and an obligation by the major to sell, all the product created by the major in a determined period pointed out by contract; the volume deal circumscribes the same contractual object to a specific volume of product.

Such contracts have, generally, a multi-year duration, variable from 3 to 5 years, and include as a purchasing object an articulated mix of products which include the main types: output deal and volume deal include, always, both television and cinema products, of current type (never previously distributed within the area of purchase) and of the re-run type (already distributed on the territory). The contract includes also a precise outline of the qualifying elements of the product and the purchasing conditions; for example, for cinema products it is possible to establish what are to be bought by the broadcaster: one option is to select, among all the movies produced by the major, only those distributed during the year within the purchasing area; for re-run movies, can be fixed a maximum amount of a yearly purchase, with the broadcaster having the 
freedom of choosing the titles from the list of the major or, alternatively, can be fixed the number of titles to be bought and their unitary value. Also for television products, in the contract are specified both the quality standards of re-run products and those of current products; for the series, we can foresee integral purchase of the series, or the buying of episodes related to only one season, with the option of the purchase of the next season. Also for television products, the contract specifies, generally, the characteristics which they need to have; for example, for buying TV series it can be indicated as requirements of the product to be bought the value of the production budget or the number of series or the format.

With the agreements of output deal and volume deal the broadcaster has the benefit of assuring itself a significant quantity of product in comparison to a disadvantage represented by the uncertainty in relation to the product which it is obligated to buy. As a matter of fact, above all, from the second year on of the contract time, even if the qualifying elements of the product indicated in the contract limit the arbitrage of the supply, the television firm will find itself in the condition of selecting an unknown product because it has been produced at a time later than the signing of the contract.

\section{Package deal}

Thanks to package deals stipulated with intermediaries, television firms take care of the necessity of integrative and variable products. Substantially, once a minimum and generic stock of products has been reassured, the package deal allows broadcasters to meet: (a) related to quantity, the needs dictated by additional use to cover hours of programming; (b) related to quality, the necessity of having at one's disposal the single and specific products already known.

According to contracts among intermediaries and majors, intermediaries can think of putting together a package deal, pure or mixed. Generally, the intermediary stipulates a package deal with the television firm offering products already bought from the major, titles which he has already at his disposal (pure package deal). In some cases, the intermediary can integrate the offer with added titles not yet available at his disposal, requested directly from the broadcaster; this is common when the television firm does not have an output or volume deal with the major represented by the intermediary and expresses the need of product of the major not included in the original package of the intermediary and not 
at his disposal. In this case, the intermediary operates in a mixed way: as pure intermediary for titles which he has already in his portfolio and as a broker for the titles which he adds to the original packet, thanks to a specific input of the television firm, but that he will have to buy from the major. In this case, the intermediary limits his exposition to risk, both in relation to the risk of not sold and to the temporal gap between the buying of rights and the sale of the same.

\section{Output/volume deal vs. package deal}

The different intrinsic characteristics of the two typologies of agreement, those used to close the deal with the major producers and those used with intermediaries, determine an impact also on the average prices generally applied in contracts (Figure 7.3).

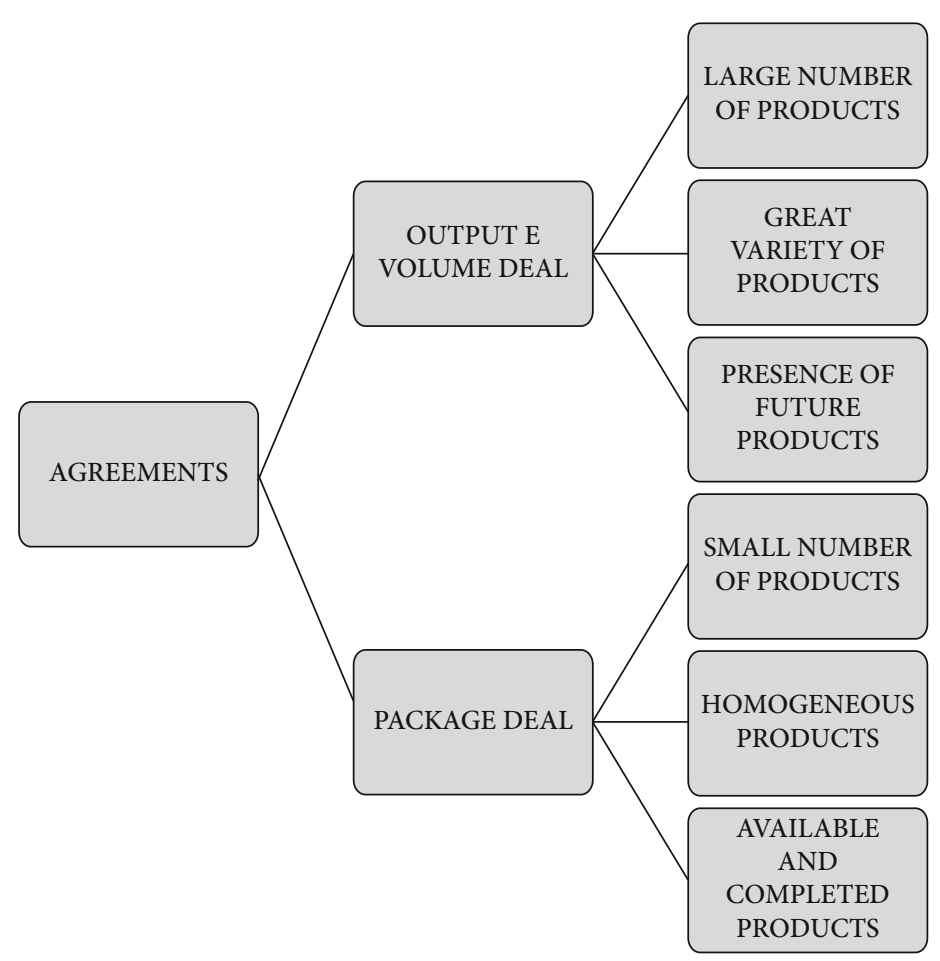

FIGURE 7.3 Output and volume deal vs package deal 
In relation to the output deal and to the volume deal, the package deal can be made up also by a limited number of titles (up to a minimum of two or three titles) and can relate only to specific typologies of product (cinema, television, current or re-run): it results, however, strongly cut out on the specific needs of the broadcaster. Naturally, it is not a perfect tailored product because even the intermediary - who has bought or needs to buy from the major - is conditioned by the need of getting rid efficiently of his own portfolio titles, minimizing the risk of storage, that is, the risk of some unsold products. Excluding such consideration, is, however, without any doubt that the package deal represents a less standardized contract, in relation to the output and volume deal, thanks to which the broadcaster overcomes the uncertainty of the product present in great quantity contracts stipulated directly with the major. Even in relation to exploitation, there are differences between the two contractual typologies; output deal, volume deal and package deal foresee specific conditions of exploitation sufficiently standardized - for cinema products, generally, 5 passages in 5 years while for television series the conditions can be more favourable. However, often, in the package deal, the broadcaster is able to obtain exploitation conditions more convenient than those usually negotiated.

The different level of standardization of the purchased basket of products, and the highest level of risk incorporated in the output and volume deal, in relation to future products still unknown at the time of the contract, determines a first strong variation in the average level of price between the two types of agreement. Substantially, the contracts stipulated by television firms with the major foresee, generally, average purchase prices lower than those stipulated with the intermediaries. So apart from the mark-up applied by the intermediary. The two types of contracts put together, as a matter of fact, types of different products with different characteristics of the package and different disclosure of the product.

Generally, the output and the volume deal are more convenient for the buying television firm in terms of the quantity of the product and of price; the package deals stipulated with the intermediary are more convenient in terms of product quality and of exploitation conditions. It is not, however, possible to compare, not even for the same type of products, the average price paid by a television firm for an output or volume deal with the price obtained on the package deals. 
The mechanisms of valuing of the products purchased, or through output and volume deal or in packets by intermediaries, introduce an additional critical element in comparing the price among various contracts.

The valuing of products happens through an escalator which applies different price levels in relation to the value of some economic variables referred to the product. For cinema products, the used parameter is the box office: the higher the box office, the higher the sale price. For television products, the more used reference parameter is the hourly cost for format; for each type of format, the higher the cost of production the higher the sale price.

So, the value of the escalators varies, first of all, in relation to the type of product because cinema and tv products are valued based on different parameters. Also for homogeneous products, it is possible to find different values: first of all, because the majors can adopt different value of the escalator; for example, two movies of two different majors which have obtained the same box office can be valued differently according to different reference escalator used by the majors. Secondly, because the conditions which influenced the class of attribute in which the product is placed can be different: for movies, for example, the dimension of the purchasing market is important (the greater is the number of viewers, greater, with the same conditions, is the value of the product); for television products, the operational efficiency of the major (the greater operational efficiency of the major, means less hourly cost of production, even to other conditions) and its commercial policies. Additionally, in the output deal and volume deal the valuing has to incorporate the risk taken on by the buyer in relation to the missing knowledge of the product due to a future production.

The mechanism of valuing of the product determines, therefore, a strong variability of prices also for products homogeneous in technicalproductive characteristics.

The mechanism of valuing of television products, and in particular the parameters of the escalator adopted by the majors, do not allow a comparison of price, not even among homogeneous products, and hinder the singling out of a reliable benchmark price.

Lastly, there is another variable able to impugn the valuing of a television product and, consequently, of the mark-up and the final price applied by intermediaries: the production model of the majors. These produce, primarily, resorting to forms of co-production with independent producers and taking on, often, also the role of national distributor. Attributing a definite value to a single product for foreign sales (allocation) can be conditioned by the convenience of the major to exploit the single product in view of the 
dynamics of profits sharing with the independent producer. So, it is reasonable to hypothesize that the major would be oriented to exploit more those titles for which the proceeds of foreign sales do not have to be shared out with the independent producer. When such titles are not of great success or of great additional value, the resulting consequence is that the best products can be valued at discount and those of less success can be valued at premium. This attitude of the majors may determine several effects on the pricing:

a) in the agreements stipulated directly between the major and the television firm, an evaluating opacity is expressed by the single title which takes on a value not easily understandable;

b) the autonomy of television broadcaster, and of the intermediaries, in valuing every single product of the sold package, can be limited, at the source, by this specific need of the major;

c) in the agreements stipulated through intermediaries, a definite break in the economic link between the two prices can be caused: that of purchase by the intermediary from the major and that of sale by the intermediary to the television firm. If the major sells to the intermediary a quality product, giving it a low value, and the intermediary, in the sale to the television firm, applies a more coherent value, it can be determined a significant distance between the two prices that, yet, does not correspond to the economic substance of the transaction, but it is only the function of an accounting criterion used in valuing the product.

The production model of the majors hit the value of the single title; the necessity to manage the allocation in function of the revenue sharing with associated producers determines a substantial impossibility to precisely reconstruct the value attributable to the single product. In sales channelled through intermediaries, such circumstance makes not significant the difference between the purchase price paid by the intermediary to the major and the sale price paid by the television firm to the intermediary.

\subsection{The economic reasons for using intermediaries in international television markets}

The presence of a long commercial chain in the market of international sales creates a different negotiation model from that used for domestic markets. In particular, the presence of intermediaries, including an extra commercial passage in relation to the direct negotiation between 
producer and broadcaster that buys the copyrights, influences the dynamics of pricing and those of the final price of the purchased product. The presence of intermediaries, other than finding justification in the services offered to selling majors and to televisions that buy, can be justified by an economic space that makes the negotiation triangularly convenient to all parties: majors, intermediaries and broadcasters. To verify the existence of such economic space, we need to recall what has already been explained in the matter of economics and of pricing and apply it to the negotiating schemes of international sales.

\section{Economics and pricing of majors}

The economics of the majors correspond to those of other producers of audiovisual works, also being characterized by the complexity of the business structure and by significant volume of production.

For the majors, the greatest difficulty in determining the pricing is that related to the estimation of revenues. If considering costs, the majors can operate looking for a greater operational efficiency which consents to knock prices down; from the revenues side, each valid alternative to limit the variability becomes the element of fundamental importance.

Resorting to intermediaries allows the majors both to cut down costs and to stabilize revenues; this allows them to apply to the intermediary, considering such advantages, reduced prices.

The Formula 5.4, which is significant of the pricing of a product, can be best expressed, in relation to the majors, as (Formula 7.1):

sales revenues $(\mathrm{p} \times \mathrm{q})=\mathrm{oc}+\mathrm{dc}+\mathrm{fc}+\mathrm{ic}+\mathrm{comr}+\mathrm{techr}$

$$
+ \text { legr }+ \text { unsr }+ \text { mark-up }
$$

where:

$$
\begin{aligned}
& \mathrm{p}=\text { price } \\
& \mathrm{q}=\text { quantity } \\
& \mathrm{oc}=\text { overhead costs } \\
& \mathrm{dc}=\text { direct costs of production } \\
& \mathrm{fc}=\text { financial costs } \\
& \mathrm{ic}=\text { insurance costs } \\
& \text { comr = completion risk } \\
& \text { techr = technical risk } \\
& \text { legr }=\text { legal risks } \\
& \text { unsr = unsold or stock risk }
\end{aligned}
$$


The overhead costs of the majors refer to the cost of employees and to the general expenses; to these are added the direct expenses of single productions; the financial expenses are connected to the financial costs of the debts and to insurance costs. The risks refer to, primarily, to those of process or of completion (that is of no completion of the work or of the realization of a final product not corresponding to the projected prototype); to technical risks, connected to the quality of materials; to legal risks; and to the unsold risk (or unsold stock risk).

The major is interested in reaching and establishing the rate of programmed profit and, to reach such an objective, can follow four ways: increase the volume of sales, fix a higher unit price, cut down costs and limit the risk exposure. The major, however, will be interested to avail itself of an intermediary if such solution allows it to meet at least one of the conditions outlined.

Considering costs, as explained, resorting to the intermediary who functions as entrepreneur allows the major to cut down the burden connected to risks - except the completion one - and to some management costs. Considering revenues, for the major, the intermediary can be functional in stabilizing or in increasing the volume of sales: (a) closing contracts for more areas; (b) reducing the volume of the unsold of various areas.

The possibility to increase through the intermediary the number of areas and to minimize the percentage of the unsold makes it convenient for the major to close the negotiation with the intermediary even at lower prices of its own technical price, because the quantity of the sold product allows, just the same, the reaching of the desired mark-up.

Saving on costs, or stabilizing or increasing revenues, allows the major to apply to the intermediary reduced prices keeping unchanged its own rate of profit expected by the investment.

A simple example helps to quantify what is expressed above. Let us assume that, using the Formula 7.1, a major would be in the position of choosing between two alternatives available for the sale of two movies: that of the direct sale to the broadcaster and that of the sale through the intermediary. Let us assume that the economics of the pricing have been estimated, for each movie, in the amount of $\$ 5$ for each typology of cost and of risk, for a total of $\$ 40$ for each movie, and that the mark-up wanted for each movie is equivalent to $\$ 10$ (25\%) for a total of $\$ 20$ on two movies': 


\section{Direct sale}

In the hypothesis of direct sale, the Formula 7.1 of the pricing would be equal to:

$$
50 \times 2=10+10+10+10+10+10+10+10+20
$$

The unit price for each movie which assures the programmed profit rate should be equal to $\$ 50$.

\section{Sale with intermediary}

Let us assume that resorting to an intermediary translates in a saving, for each one of the two movies, of $\$ 1$ on overhead costs, on financial costs and on legal costs, and to an annulment of technical and unsold risks, for a total saving of $\$ 16$ on two movies. The pricing formula would signify a different equilibrium among revenues and costs:

$37 \times 2=8+10+8+10+10+8+20$

The unit price which the major could apply to the intermediary on a single movie, leaving unchanged its own profit, would be equal to $\$ 37$, $\$ 13$ less of the applicable in the hypothesis of direct sale.

Resorting to the intermediary, creates for the major an economic space for the application of lower unit prices in relation to the applicable price in the direct sale; selling to the intermediary, the major can apply prices below the price that it should attribute in the direct sale to reach the same rate of return.

\section{Economics and pricing of intermediaries}

Generally speaking, the economics of the pricing of an intermediary correspond to that of any other provider of services. The activity of intermediation is looked at as a service that, generally, is produced following the purchase, represents intangible goods, presents significant fixed costs whose level varies according to the nature of the activity of intermediation and offers - stand-alone - low economies of scale.

The difficulty in determining the technical price makes revenues an even more significant variable in the process of pricing. In relation to the economics, the intermediaries are naturally prone to focus their attention on the estimated revenues, rather than on a more efficient and accurate analysis of costs. Since, generally, the services are first sold and then produced, the intermediary has the possibility to estimate revenues with greater accuracy. 
Additionally, the activity of intermediation is characterized by a demand inelastic to prices: clients tend not to react to price changes or, alternatively, apply minimum changes on the quantity requested; rarely, facing a price variation, clients are inclined to change the furnishing firm.

On the contrary, the client pays attention to the perceived value, valuing on one hand, his need and the investment quality, on the other hand, the savings in terms of non-monetary costs which the work of the intermediary brings about. Also for this reason, the price of competitors loses part of its strength.

Such circumstances permit, generally, to the intermediary more possibilities to apply high mark-up and final prices, without incurring in a decrease of purchasing orders or losing the client.

For such reason, the pricing of the intermediation activity adopts less to a "cost-based methodology", and it is strongly conditioned by the orientation to maximize revenues. It is important, therefore, to understand what is the economic space to the pricing policy of the intermediary.

For an intermediary negotiating television copyrights the Formula 7.1 related to the pricing of the product takes on a different configuration (Formula 7.4) in relation to the one of the producing major; for the intermediary, the costs of completion are not present anymore, while the direct costs are connected to the purchase of product by the majors and are, consequently, comparable to the cost of raw materials of production of a traditional industrial firm:

$$
\begin{aligned}
\text { sales revenues }(\mathrm{p} \times \mathrm{q})= & \mathrm{oc}+\mathrm{dc}+\mathrm{fc}+\mathrm{ic}+\text { techr }+ \text { legr } \\
& + \text { unsr }+ \text { mark-up }
\end{aligned}
$$

Also for the intermediary, as for the major, the objective is to maximize profit. However, compared to the major, the intermediary has a more rigid and less foreseeable structure. In terms of strictness of costs, contrary to the major, the possibility to outsource specific functions is very limited, because the intermediary represents himself as the commercial link with the buying broadcaster. In particular, technical, legal and unsold risks can take on ex post values much more important than those hypothesized. It is sufficient to think about the unsold risk: the cost of the unsold product can determine heavy loss on single negotiations. When the unsold risk is managed the intermediary has also borne a financial risk explained by the temporal gap elapsed between the buying date of the copyright by the major and that of sale to the broadcaster. 
Considering costs and risks, therefore, the intermediary can only activate the lever of his own managerial efficiency that, however, is limited by the difficulty, typical of services, in obtaining significant economies of scale.

Therefore, the intermediary uses the revenues as a main lever of his own pricing. Since the revenues depend on the price and on the quantity sold, he will try to sell more or at a higher price. The uncertainty about the level of costs and of risks translates itself, however, in the necessity to apply high mark-up, which affects the price, to obtain the margins of profit desired. The economic space produced by the negotiation with the major, therefore, makes it easy to apply a price compatible with the needs of the intermediary.

Let us look again at the example of the two movies bought by an intermediary at \$37 each; let us assume that, for the sale of the movies to the broadcaster, the costs which the intermediary faces are the same of the half of those incurred by the major, that the intermediary attributes the unsold risk of the specific negotiation related to the two movies a quota part of his general risk of unsold goods equal to \$5, and that the profit rate desired is the same of that applied by the major, therefore the $25 \%$ corresponding to almost $\$ 17$ of mark-up per movie. We would have:

$69 \times 2=5+74+5+5+5+5+5+34$

The intermediary, to get the unitary rate of profit desired (\$17) would need to apply a price equivalent to $\$ 69$ per movie; this way he would obtain almost a yield of $25 \%$. In relation to the purchase price of the major, equivalent to $\$ 37$, the intermediary would apply an increase of almost $86 \%$ - that however would result equivalent to $38 \%$, if compared with the price of $\$ 50$ that the major would apply to the broadcaster in the case of direct sale.

In case the intermediary perceived the uncertainty of high costs and risks, his pricing should incorporate such prevision. Let us assume that the intermediary estimates it probable that one of the two movies of the bought package from the major is unsold; the pricing formula of the only sold movie, incorporating such risk, should however include the purchase cost of the unsold movie, and should cut down the value of costs from technical and legal risks not met because of the no sale, other than the mark-up on the second movie. So we would have:

$116 \times 1=5+37+5+5+2.5+2.5+(5+37)+17$ 
If the intermediary would want to insure himself against the risk of one unsold movie, keeping his mark-up on the sold movie unaltered, he should sell the movie at the price of $\$ 116$, with an increase of over $300 \%$ in relation to the purchase price, and of almost $230 \%$ in relation to the price that the major would apply to a direct sale to the broadcaster.

When the intermediary operates on an inverted cycle, the dynamics of pricing do not change in their basic structure: the unsold risk transforms in supplies risk, the financial risk is limited but, in the majority of cases, continues to be so.

\section{Valuing the advantage of using intermediaries}

The existence of an economic space that justifies the presence of an intermediary, therefore, needs to be verified, first of all, valuing the determinants of risks and costs incurred by the intermediary, secondly considering as a parameter the gap between the price applied by the intermediary to the broadcaster and the hypothetic target price applied by the major in the direct sale, and not comparing the sale price of the intermediary with that of the purchase from the major.

The gap between the purchase price of the intermediary from the major and the sale price to the broadcaster is not representative of the increase of cost taken on by the broadcaster, and consequently the burden to resort to the intermediary; a more correct estimate could be made comparing the price set by the intermediary with the hypothetic target price that the major would have applied to the broadcaster through a direct sale.

However, even the comparison between the price applied by the intermediary to the broadcaster and that applied by the major through direct sale, for how right it is in an optic of accounting methodology of pricing, is however impugned by the various negotiating and contractual structures and by the different mix of the products sold in the schemes of direct sales and in those through intermediaries.

\subsection{The financial model inside the film market}

It has been clarified that available funding sources to the film industry come from soft money and pre-sale of copyrights. With the only exception of the USA, the access to private funds is residual and represents a modest amount of the total budget (Figure 7.4). 


\section{Public funding}

Culture is one of the cornerstones of European policies; public aids to the audiovisual industry are allowed and designed as part of the internal and external policies of the European Union aimed at implementing the 2005 UNESCO Convention².

Due to the recognized cultural role of the audiovisual industry, every European country has gradually adopted various means of public support. In Europe, public aids are historically cinema-oriented; nevertheless, the digital revolution fostering the co-existence of traditional linear media and new digital and non-linear services has gradually extended the sphere of action of public supports to all cultural audiovisual products.

At a European level, the legal framework for public financing is represented by the Cinema Communication ${ }^{3}$ and the Creative Europe Programme, which provides the "sub-programme MEDIA" dedicated to the audiovisual industry ${ }^{4}$. The rationality behind the financial supports to cultural sectors is that the culture is a key tool to promote the European single market and to foster social integration through the respect of cultural diversity. The so called "cultural exception" allows member States to grant support to the industry in accordance with the commitment of not distorting competition. In this respect, European and national public funds are intended primarily for small companies - mainly of the cinema sector - with low market share and independent from broadcasters, which are assumed not in need of public support and not always oriented at cultural products. Besides, aids to the audiovisual industry are allowed in accordance with the EU State aid regulation that sets limits to public support calculated in percentage of the product total budget: the greater the degree of cultural-

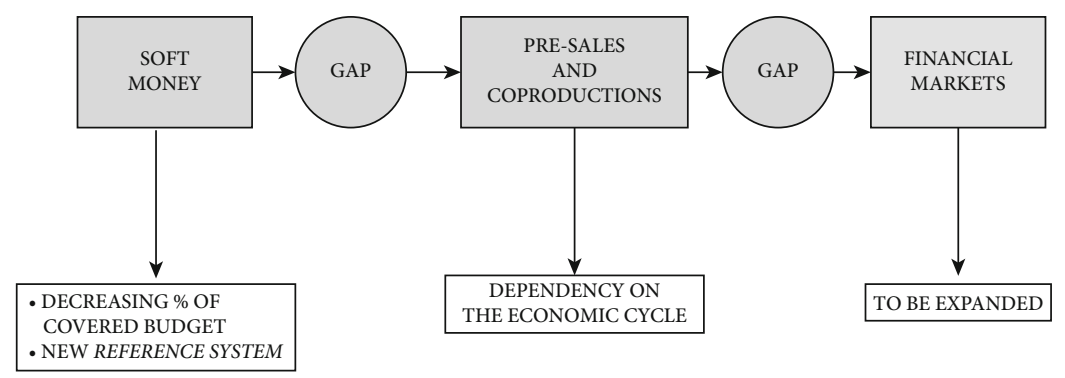

FIGURE 7.4 Funding cycle of cinema firms 
ity of the product supported, the higher the percentage of the budget that can be financed by national public funds.

At a country level, Governmental aids for the audiovisual business consist of national and local (regions, counties, councils) support. The national support, which involves the all production chains of the audiovisual industry - development, production, distribution, exhibition - is intended for the products, and funds are channelled through grants, soft financing or tax incentives, and can be issued automatically or through selective screening, based on specific reference systems. Local aids are mainly conceived to support producers and exhibitors, principally through the refurbishing/conversion of cinemas.

Public funding to the cinema sector has played in the last years a role always more marginal in quantitative terms. The percentage quota covering the budget by public funds has decreased gradually in time, considering the financial crisis and the decreasing public resources allocated to cultural sectors. Only short and documentary films, in relation to the degree of culturality and the recognized difficulty in tracing funds on the market, are mainly financed by public funds.

In a modern context, however, the importance of public funds in the financial cycle of the cinema industry is of a qualitative type. On one hand, public involvement has the task of indicating the cultural value of the product; on the other hand, it has the unquestionable function of being the strength of initiating the process of funding. This is explained by the fact that public funds are requested directly by the producer, without resorting to a distribution firm, already in the development phase and, therefore, represent, often, the first timely financing.

\section{Pre-sale of copyrights}

The movie industry is the most evident example of a financial model based on the discounting of future revenues. In quantitative terms, as a matter of fact, the financing of a movie product is mainly met by the pre-sale of copyrights. From a financial point of view, the movie industry is characterized by a significant mismatching between inflows and outflows; the proceeds, as a matter of fact, begin to translate into money only some months after the end of the production, with theatrical copyrights, while the revenues resulting from the other copyright markets can be obtained even after years from the premiere of the product. For such reason, the mechanism of pre-sales which allows a partial anticipa- 
tion of the revenues of future copyrights transfer, is fundamental in the financial equilibrium of cinema production firms.

The market of television copyrights represents one of the most important sources of the financing of cinema products. Until the 7os, the greatest source of revenues for the cinema coincided with the box office and the producer financed the movie asking for an advance on future theatrical proceeds. Afterwards, a decrease in movie-goers and an increase in television viewers have made television extremely important, both in an economic optic and the financial one.

Either in the case in which the producer makes a co-production with the broadcaster or in the case in which he produces autonomously, a significant part of financial funds necessary to produce the movie comes from the television firm which finances the work by pre-buying television copyrights. In such circumstances, the amount deriving from the pre-sale of the cable-rights corresponds, for the independent producer, to a revenue, and to a financing source.

In Europe, the importance of television broadcasters in the financing of the cinema sector is, therefore, stressed also by specific regulation: having to consider minimum percentages of programming of national and European movies, television broadcasters are indirectly subject to an obligation to invest a percentage of their own resources in cinema products. Such rules create another connection between the financial model of broadcasters and that of movie producers.

Generally, when the broadcaster participates in the project as a co-producer, television copyrights are negotiated in the co-production agreement directly between the broadcaster and the movie co-producer.

When the film company produces autonomously, the sale of television copyrights of the movie are often carried out by a distribution firm which takes care of the sale of the movie copyrights on all potential markets of exploitation. Even if the producer could negotiate autonomously his own copyrights, by praxis he relies on a distribution firm or, alternatively, can combine the two options. The distributor, other than taking care of the promotion and of the launching of the film, takes on, therefore, a decisive role for the economic exploitation of the work closing, for the producer, sale deals of copyrights on different channels of exploitation, domestic and international. In the cinema market, the distributor, generally, assures the producer an advance on future revenues - so called "minimum guarantee" - which he recovers primarily as the proceeds show in money. In such case, the distributor takes on 
the role of the leading external funder of the movie. Considering such service, the distributor asks for a commission and an absolute priority in the distribution of revenues up to a concurrence of the applied commission, of the expenses incurred for the distribution and the launch, of the amounts lent under a minimum guarantee title; only after the distributor has recovered these amounts, the revenues of the movie could be shared between the producer and the distributor himself.

To fully understand the financial model of the cinema industry it is necessary, therefore, to understand in detail the types of agreements generally used among producers and distributors.

More specifically, film production financial plans normally include recoupment agreements between producers and distributors: the so called "distribution deal".

The understanding of the recoupment agreement stated in the distribution deal is an essential requirement for a first evaluation of the reliability of the producer/distributor.

\section{Typologies of distribution deals}

There are two standard types of distribution contracts: gross deal and net deal.

In the gross deal contract, proceeds originating from the exploitation of a film are divided between producer (licensor of the rights) and distributor (licensee), according to certain percentages defined in the contract. The distribution company, due to the financial support provided for production, recovers its expenses according to such percentage.

The producer and the distributor will register a profit only in the case in which competency revenues, divided according to what stated in the distribution contract, will be above the costs incurred.

In the net deal, more commonly used, the revenues are allotted, first of all, to cover the anticipated expenses by the distribution (minimum guarantee, launch and edition expenses) and, only the remaining amounts are divided between producer and distributor according to the percentages established. Since the proceeds of the theatrical are not always sufficient to cover the expenses anticipated by the distribution, the net deal foresees, generally, a clause of cross-collateralization that acknowledges the possibility of using the revenues from the exploitation markets following the theatrical to reintegrate the distributor of the incurred costs. Such type of agreement states that the incurred expenses by the distribution (minimum 
guarantee and expenses of launch and edition) could be considered as advances granted to the production and, so, represent credits which the distribution has towards the producer. Such credits will be consequently reimbursed, having priority on revenues generated by the film.

The net deal foresees always the definition of one specific mechanism of revenue sharing between the producer and the distributor. Even if by praxis each agreement can have different characteristics in relation to the specific needs of the parts, and to the peculiar nature of the project, it is possible to trace two types of revenue sharing methodologies: lump sum (cost off the top) and dynamic (pure net deal).

The costs coverage and the subsequent revenues sharing between producer and distributor are carried out differently depending on whether the cost off the top method, rather than the pure net deal is used:

- the cost-off the top says that the revenues are destined, primarily, to cover distribution expenses and the minimum guarantee; only after are the revenues divided between producer and distributor based on the percentages established;

- the pure net deal says that the distributor keeps, from the first revenues, a distribution fee established by contract; the next revenues are destined primarily to cover distribution expenses relying only on the producer quota - and only after are they divided between producer and distributor based on the percentages set by contract.

\section{An example of net deal agreement}

An example of a scheme of net deal helps to understand better the forms of revenue sharing between distributor and producer. The following example refers to an art house film, with a reduced budget, which has a significant box office and that offers the opportunity of exploiting copyrights even on markets post-theatrical.

Supposing (Table 7.1), that the movie in question has a production cost of $€ 550,000$. Supposing, moreover, that in the distribution agreement would be established a minimum guarantee, in favour of the producer, equivalent to $€ 100,000$ and that distribution expenses result equivalent to $€ 200,000$.

Suppose, then, that following the release, and considering the agreements of pre-sale, the revenues from the various markets are equivalent to $€ 250,000$ per box office (considered already net from the percentage 


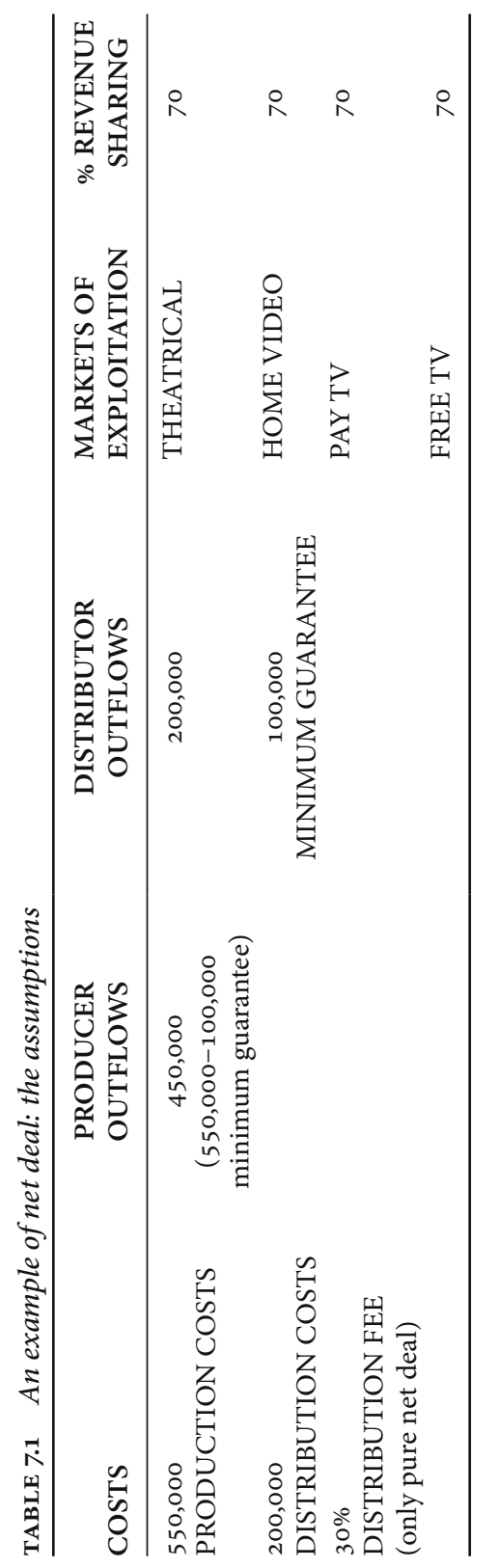


detracted by exhibitors), €50,000 for Home Video, €100,000 for Pay TV and $€ 150,000$ for Free TV.

Suppose, lastly, that in the agreement would be established a revenues sharing mechanism, imagining that such distribution gives the producer $70 \%$ of revenues resulting from the exploitation of copyrights on various markets (theatrical, home video, Pay TV and Free TV), and to the distributor the remaining $30 \%$.

In the hypothesis that the distribution contract followed the scheme of the cost off the top (Table 7.2), considering the cross-collateralization mechanism, the proceeds from box office and of Home Video are entirely destined to cover the anticipated expenses by the distribution (distribution expenses plus minimum guarantee assured to the producer). Only for revenues from the sale of copyrights to television follows the distribution between producer and distributor, according to the quotas established in the distribution agreement.

In the example given, then, the distributor recovers the anticipated expenses $\left(€_{300}, 000\right)$ and obtains a profit equivalent to $€ 75,000$, while the producer registers a loss equivalent to $€ 275$,000, that is the net amount between the total production costs $(€ 550,000)$ and the proceeds that, according to the agreements, has been able to use to cover such costs $(€ 100,000$ from box office and home video, to cover the minimum guarantee advanced by the distributor, and $€ 175,000$ from television sales to cover other production expenses incurred). In such case, the producer could reach the covering of expenses, and eventually get a profit, only through access to other exploitation markets of copyrights, or through

TABLE 7.2 Cost off the top revenues sharing

\begin{tabular}{lccc}
\hline & $\begin{array}{c}\text { AGGREGATED } \\
\text { REVENUE } \\
\text { WATERFALS }\end{array}$ & $\begin{array}{c}\text { PRODUCER } \\
\text { SHARE } \\
70 \%\end{array}$ & $\begin{array}{c}\text { DISTRIBUTOR } \\
\text { SHARE } \\
\mathbf{3 0} \%\end{array}$ \\
\hline THEATRICAL: 250,000 & 250,000 & ----- & $-\cdots---$ \\
HOME VIDEO: 50,000 & 300,000 & ----- & ---- \\
RECOVERY OF & 300,000 & --- & \\
DISTRIBUTION COSTS + & & & \\
MINIMUM GUARANTEE & & & \\
PAY TV: 100,000 & 400,000 & 70,000 & 30,000 \\
FREE TV: 150,000 & 550,000 & 105,000 & 45,000 \\
TOTAL: & 550,000 & 175,000 & 75,000 (profit) \\
THEATRICAL + & & & \\
FIRST SALES & & & \\
\hline
\end{tabular}


copyrights sales on foreign markets, or still through second sales of copyrights on the national market.

Following a dynamic schema, typical of the pure net deal, generally used, the revenue sharing is more complex. First of all, as said before, the methodology includes always a commission on distribution - calculated on theatrical revenues - to cover the quota share of indirect structural costs of the distribution firm attributable to the specific project, and not included among the costs of edition and launch.

In such a scheme, then, the revenues resulting from the various forms of copyrights exploitation are distributed only theoretically according to the percent quotas set in the distribution agreement. Such distribution does not coincide with the true economic availability of the producer and of the distributor of their due sums. As a matter of fact, the priority of covering the anticipated expenses by distribution (distribution costs plus minimum guarantee) is met, initially, weighing on only the quota belonging to the producer. Only in the hypothesis when the producer quotas, related to the various exploitation markets, and accumulated, are not sufficient to cover the anticipated expenses, the coverage would be met also weighing on the quota nominally belonging to the distributor.

In the pure net deal, as shown by the example, a quota of the theatrical revenues is destined, first of all, to cover the distribution fee (Table 7.3). Once the distribution fee is subtracted, the producer quotas connected to the box office revenues (net from the distribution fee), to copyrights sales of home video, of Pay TV and of Free TV are destined, following the agreement and considering the mechanism of crosscollateralization, to cover the minimum guarantee and the distribution expenses. In the example given, from this project the distributor gets a net profit of $€ 143,500$, while the producer registers a loss equivalent to $€ 418$, Ooo, that is at the net balance between the total cost of production $(€ 550,000)$ and the revenues that, according to the agreement, have been destined to cover production costs $(€ 100,000$ to cover the minimum guarantee anticipated by the distributor, and $€_{32}$, ooo from the transfer of copyrights to Free TV to be used to cover the other production costs).

Also in such case, the producer will be able to reach costs coverage, and eventually obtain profits, only through access to other markets of copyrights exploitation, or through the sale of copyright on foreign markets, or through second copyrights sales on the national market. In 


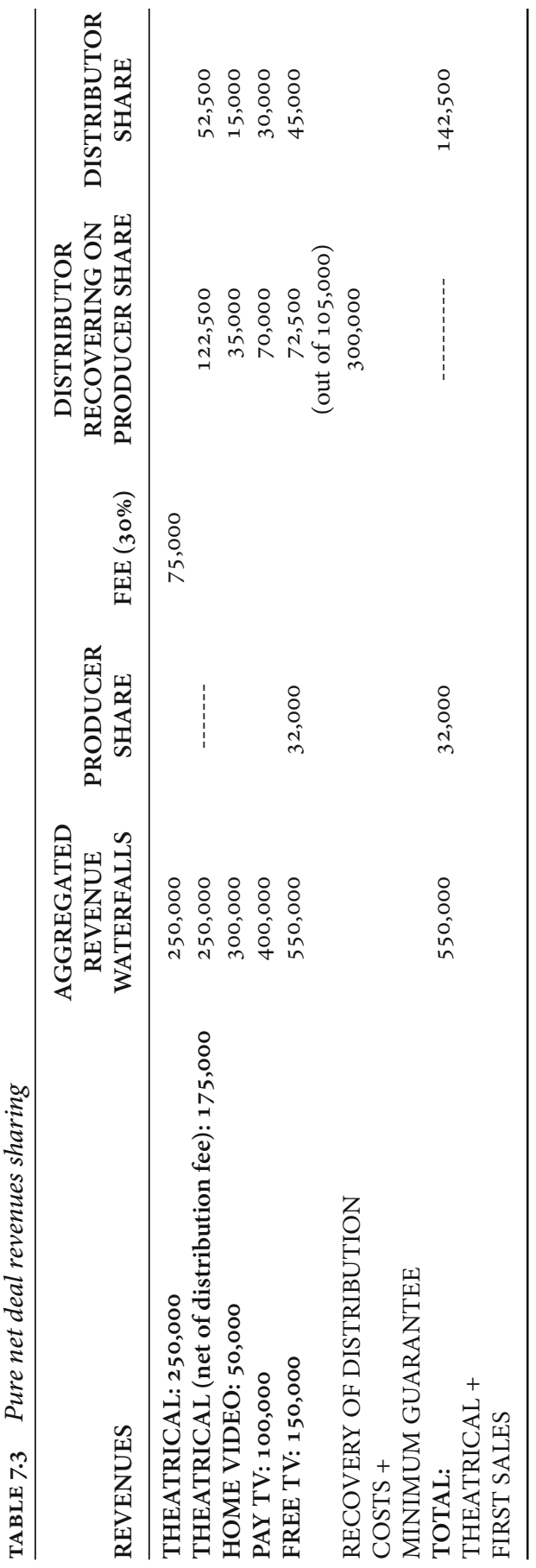


the pure net deal method, therefore, the distributor recovers his expenses weighing, first of all, on producer quotas: using distributor quotas to cover distribution expenses is residual and eventual; in the cost off the top, the producer and distributor quotas are added to reach the objective of covering costs: the distributor participates with his own quotas to cover the expenses incurred.

Whatever might be the performance of the product on various markets, in the distributor view the pure net deal is always more convenient; for the producer, on the contrary, the cost off the top represents the most advantageous way of distribution of revenues because it allows speeding up the recovery of expenses.

In reference to the revenues sharing, it is easy to notice how the dynamics of theatrical strongly influence the mechanism: with highly successful box office products the producer will regain possession of his own quotas of revenues more rapidly, according to the percentages established by contract, whether is used the cost off the top or the pure net deal.

The example illustrates a case which, in spite of a fair box office success, the total accumulated revenues generated by the theatrical and by first sales $(€ 550,000)$ do not cover the total cost of production and distribution $(€ 750,000)$ while they cover, nominally, all the costs of production $(€ 550,000)$. It is easy to see, however, how applying the cost off the top and the pure net deal, the producer does not recover the expenses incurred. The distributor registers, in both cases, a profit, that, therefore, is more meaningful in the case of pure net deal.

The recoupment mechanisms included in distribution deals conventionally used determine, therefore, a mechanism of revenues sharing which assures a faster reaching of the economic equilibrium by the distributor. The producer's ability to increase profits depends, firstly, on the performance generated by the product at the theatrical level and is, then, strictly correlated with the artistic strategy adopted. Such contractual strength linked to the distributor finds its own ratio in the ability of the distributor himself to assure, at the same time, money for the production expenses and the closing of the circuit of the copyrights exploitation chain, and takes for granted the possibility that the producer could exploit the same copyrights on others and on different geographical markets. The choice between net deal and gross deal, between cost off the top and pure net deal, the same as the setting of percentages of the 
producer and distributor quotas depend, mainly, on the amount of the minimum guarantee assured to the producer and on the market power which the distributor can claim in assuring a profitable negotiation of the copyrights of the work. In synthesis, the distributor, on one hand is he who guarantees access to exploitation markets, and on the other hand takes on the role of a traditional financier, assuring a minimum guarantee; for such reasons, he has priority on waterfalls of revenues of the movie which allows him to reach an economic equilibrium more comfortably and more rapidly. For the producer, the cost of the distributor involvement is not sustained by an interest payment, as it would happen in case of a traditional financing, but in access to revenues conditioned by the main fulfilment of the distributor.

The types of agreement among producers and distributors bring out clearly how the financial model of the movie industry is strongly based on prospective proceeds. The presence of external financing is substantially absent and, in fact, substituted by a particular role taken on by distribution firms. Due to the financial crisis, the market is increasingly experiencing distribution deals with no minimum guarantee provided by distributors. This results in a more convenient revenue sharing mechanism for producers, who in contrast have to face a shortage of internal financial resourcers.

\subsection{The financial model of the audiovisual web market}

The economics at the base of the production process of web native audiovisual products, strongly conditions also the financial model.

The production dynamic of web products, centred on the self-reference of filmmakers, does not generate the urgency to implement sophisticated financial models. The costs, generally met by the same filmmakers, are designed on real resources of the authors; the amateurish nature of the product does not aim at looking for revenue sources on exploitation markets. Not foreseeing external financing in the production process, the objective to obtain revenues, therefore, is not even important to honour eventual debts towards third-party counterparts.

The outlined elements are characteristic of the audiovisual web native products promoted by filmmakers and small production companies. 
The need of a more developed financial model, however, could be presented for that target of filmmakers who, having gone through an amateurish initial phase and gotten to a second step, have the need to upgrade the artistic and technical standards of their own productions. The legitimate artistic ambitions do not agree with the absence of a financial model that, therefore, needs the certainty of revenue sources and of a budget proportioned to the real commercial potentialities.

For such reasons, it is easy to understand the necessity, also for the web, of a well-defined financial model. This, rather than being promoted by filmmakers, or by their associations, could find a valuable impulse in the SVoD market, where OTT players are active in releasing original and nonoriginal contents and Online Video Aggregators (OVA) are emerging. OTT and OVA are interested in filling their own platforms of innovative content. In such optic, it is possible to imagine that, in the near future, there could be new players that would put together on specific platforms of web products of audiovisual nature. Such platforms could follow a non-profit model or could individualize models of revenue sharing of advertising proceeds between the platform that takes care of content, the telecom companies and filmmakers. The various mechanisms of sharing between advertising agents, telecom and platforms, together with the weak attention of filmmakers towards the commercial potentiality of their own products and the exploitation of copyrights, do not make it easy to implement financial mechanisms that reward the authorial work of filmmakers. The entry on the market of players able to package baskets of products from different filmmakers would certainly foster the process. In the future, it will be necessary to have more transparency on the types of agreements which platforms stipulate with advertising agents, and of those which the single platforms stipulate with telecom, together with a re-visitation of web products copyrights legal framework.

In the financing process of web products, additionally, an important role could be played by public resources; public support, in fact, should be always more concentrated on cultural and low budget products promoted by young authors. The introduction of fiscal incentives specific for web native audiovisual products, for example, together with direct funds destined to development costs, could represent a valid option for a financial model able to support the growth of the web audiovisual market and young authors. 


\section{Notes}

1 The overhead costs represent the share of attributable costs to the two movies; the unsold risk is estimated equal to the cost of production for the single movie (\$5).

2 UNESCO (2005); EC (2012).

3 The European Commission has approved a revised version of the Cinema Communication: 2013/C 332/o1.

4 Creative Europe is the new EU framework programme for the Cultural and Creative sectors (CCS) for the 2014-2020 Multi-Annual Financial Framework (MFF). Bringing together the previous Culture, MEDIA and MEDIA Mundus programmes under a common framework, it creates a new Guarantee fund to improve access to finance (COM/2011/0786).

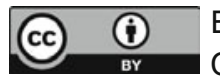

Except where otherwise noted, this work is licensed under a Creative Commons Attribution 3.0 Unported License. To view a copy of this license, visit http://creativecommons.org/licenses/by/3.0/ 